\title{
Conceptual structure and social choice: A replication under modified conditions '
}

\author{
SIEGFRIED STREUFERT ${ }^{?}$, RONNIE G. BUSHINSKY AND CARL H. CASTORE \\ DOUGLASS COLLEGE, RUTGERS-THE STATE UNIVERSITY
}

Social choices of Ss were factor analyzed to determine whether simplicity-complexity of conceltual structure, openness, and speed of closure determines characteristic social choice patterns, other than choice clusters (sntall grouts of Ss chosing primarily each other). It was found that social choices are affected by simplicity-complexity and by openness. Speed of closure had a comparatively small effect. It was conchided that conceptual structure and openness are important but incomplete determinants of interpersonal attraction as expressed in social choice.

In some recently reported research, Streufert, Castore, Kliger, \& Driver (1967) have been concerned with the effect of conceptual structure on social choice. These authors have shown that differences in the simplicity-complexity dimension of conceptual structure accounts for $20-40 \%$ of the variance in social choice matrices. By use of a factor analytic technique, Streufert et al demonstrated that factor defined choice clusters (small groups of Ss choosing primarily each other) differ from each other in conceptual structure.

In the experiment of Streufert et al (1967), Ss were asked to list those members of the subject population with whom they would be willing to talk at a party, work on an academic task, etc. Some listed as many as seven others, while other Ss listed few or noothers. As a result of these differing choice frequencies, all emerging factors were defined by choice clusters.

This research is concerned with the effect of conceptual structure and two related variables on social choice characteristics, other than choice clusters. Similar procedures, as well as the same factor analytic technique (Horst, 1965) employed by Streufert et al (1967) are used. However, Ss were requested to make an identical number of choices, so that primary sensitivity of the factoring procedure to choice clusters would be avoided. Subjects

Thirty-nine female undergraduate students comprising all residents of a single wing in an eastern university dormitory were tested with the sentence completion test (SCT) (Schroder \& Streufert, 1963; Schroder, Driver, \&
Streufert, 1967) to measure conceptual structure, openness, and speed of closure. Scores for conceptual structure in this sample were distributed as follows: Score 1 through 2 (simple, no capacity to differentiate or integrate), $16 \mathrm{Ss}$; Score 3 through 6 (moderately complex-integrators), 10 Ss. Highly complex Ss, Scores $1+$ through 17 (high level integrators), were not present in this sample. Openness and speed of closure were scored on a three point scale. Scores in this sample were distributed as follows: low openness (closedness, Score 1)-11 Ss, medium openness (Score 2) $-14 \mathrm{Ss,}$ high openness (Score 3)-14 Ss; low speed of closure (Score 1)-15 Ss, medium speed of closure (Score 2) $-18 \mathrm{Ss}$, high speed of closure (Score 3) $-6 \mathrm{Ss}$.

\section{Procedure}

All Ss received a sheet of paper with instructions reading as follows: Indicate below the names of individuals living in this wing ONLY with whom you would prefer to speak at a party. Below the instructions were five numbered blank spaces. Ss were given 3 min for their five choices. Choices were made privately.

The matrix of choices received by Ss was factor analyzed in accordance with the procedure recommended by Horst (1965). Since visual inspection of the data suggested that the unrotated factors approached simple structure, and since it was desirable to maintain any loadings of individuals across factors, the interpretation was based on the unrotated factors.

Results

Five factors, each accounting for more than $6 \%$ of the variance in the choice matrix, were extracted. Loadings of the factors, percentage of variance accounted for by each, and Ss' mean scores on all measures, are presented in Table 1 . In addition, Table 1 lists the mean number of times Ss defining each factor were chosen, the number of times their choices were reciprocated, and the proportion of reciprocated choices to the times they were chosen (here called reciprocity). MannWhitney $U$ tests were used to analyze for differences among Ss defining the five factors on simplicity-

Table 1 Mean scores for Ss defining Factors 1 through 5

\begin{tabular}{cccccccc}
\hline Factor & $\begin{array}{c}\text { Variance } \\
\text { Accounted for }\end{array}$ & $\begin{array}{c}\text { No. of } \\
\text { Times chosen }\end{array}$ & $\begin{array}{c}\text { Reciprocal } \\
\text { Choices }\end{array}$ & $\begin{array}{c}\text { Reciprocity } \\
\text { Score }\end{array}$ & $\begin{array}{c}\text { Complexity } \\
\text { of Conceptual } \\
\text { Structure }\end{array}$ & $\begin{array}{c}\text { Speed } \\
\text { of } \\
\text { Closure }\end{array}$ & Openness \\
\hline 1 & $3.759=9.64 \%$ & 6.0 & 3.14 & .523 & 1.57 & 2.00 & 2.86 \\
2 & $3.276=8.40 \%$ & 6.2 & 1.60 & .258 & 6.80 & 2.00 & 1.80 \\
3 & $2.901=7.44 \%$ & 6.0 & 2.86 & .475 & 3.71 & 1.29 & 1.43 \\
4 & $2.721=6.98 \%$ & 3.0 & 1.44 & .480 & 8.11 & 2.12 & 2.34 \\
5 & $2.387=6.12 \%$ & 5.6 & 2.40 & .428 & 8.80 & 2.00 & 2.60 \\
Total & $15.044=38.57 \%$ & & & & & & \\
\hline
\end{tabular}


complexity of conceptual structure, speed of closure, and openness. The following comparisons were significant: (1) Conceptual structure-Factors 1 vs 2 ( $p<.001$ ), 1 vs 3 ( $p<.027), 1$ vs 4 ( $<<.002), 1$ vs 5 ( $<<.005), 2$ vs 3 (p<.015), 3 vs $4(p<.05), 3$ vs $5(p<.01)$; (2) Speed of Closure -2 vs $3(\mathrm{p}<.001), 3$ vs $5(\mathrm{p}<.012)$ : (3) Openness -1 vs 3 ( $p<.001), 2$ vs 3 ( $p<.037), 3$ vs $4(p<.002)$, and 3 vs 5 ( $p<.037)$.

Discussion

Only the first of the five factors obtained in this analysis is defined by Ss forming a choice cluster. This cluster is made up of seven Ss, who vary considerably in speed of closure, but are highly uniform in openness and simplicity of conceptual structure.

Factor 2 is defined by five Ss who are chosen reasonably often, but who rarely make choices that are reciprocated. Consequently, their score is quite low. They are medium in speed of closure and openness. Moderate scores on conceptual structure identify them as differentiators. Based on complexity theory (Driver \& Streufert, 1966; Schroder et al, 1967), one would predict that differentiators should respond to a number of components (persons) in their environment independently. In other words, they should not require similarity of the component (persons) to themselves or, for that matter, to each other. They might consequently have chosen any others even if similarity (and consequently reciprocity) was not present. Although the Ss defining this factor are significantly different in conceptual structure from Ss defining Factors 1 and 3, they barely miss significant difference when compared with the Ss defining Factors 4 and 5 . Ss in Factors 4 and 5 show mean scores in the integration rather than the differentiation range of complexity. In other words, the results of this study do not warrant strong statements describing differences due to differing degrees of complexity between differentiators and integrators.

Factor 3 is defined by seven Ss who neither chose each other nor show any similarity in their own choice characteristics. However, other Ss appear to have considered them to be similar. When others chose one of the Ss defining this factor, they chose at least (any) two others which also define this factor. What then is the similarity found by others with relevance to this group? These Ss are quite similar to those defining Factor 1 in simplicity of conceptual structure, in the number of times Ss are chosen, and in reciprocity. However, they are low in speed of closure, and quite closed. Again a comparison between Factors 1 and 3 on speed of closure barely misses significance (although comparisons to
Factors 2 and 4 are significant). However, a comparison of openness-closedness between Factor 3 and all other factors is significant.

Factor \pm is defined by nine Ss who are rarely chosen. They are generally medium in speed of closure and openness, but are of complex conceptual structure (integrators). This group of Ss apparently represents an "unpopular" group of complex persons. Inspection of their own choice pattern indicates some choices of each other. If five choices had not been forced, this group of Ss might well have produced a lower order choice cluster factor.

Factor 5 is similar to Factor 3. Again, other Ss appear to have seen some communality between the persons defining this factor. When others chose one of the persons defining this factor they chose at least (any) one other person defining this factor. With one exception, these Ss are of complex conceptual structure (integrators) and highly open. However, significance is only obtained for conceptual structure for comparisons with Factors 1 and 3, and for openness for comparison with Factor 3. No significant differences with Factors 2 or 4 are obtained. In other words, neither openness nor complexity is able to explain the lack of "popularity" of Ss defining Factor 4, as compared to Ss defining this factor.

In conclusion, it appears that openness and particularly complexity of conceptual structure account for some of the differences in social choice patterns beyond choice clusters (for which a relationship was established in earlier research).

\section{References}

DRIVER, M. J., \& STREUFERT, S. Group composition, input load and group information processing. Institute for Research in the Behavioral, Economic and Management Sciences, Purdue University. Institute Paper No. 142, 1966.

HORST, P. Factor analysis of data matrices. New York: Holt, Rinehart \& Winston, 1965.

SCHRODER, H. M., DRIVER, M. J., \& STREUFERT, S. Human information processing. New York: Holt, Rinehart \& Winston, 1967.

SCHRODER, H. M., \& STREUFERT, S. The measurement of four systems of personality structure varying in level of abstractness: Sentence completion method. Princeton University: ONR Tech. Rep. No. $11,1963$.

STREUFERT, S., CASTORE, C. H., KLIGER, S. C., \& DRIVER, M. J. Conceptual structure and interpersonal attraction. Rutgers University: ONR Tech. Rep. No. 3, Contract-N00014-67-0115-0002.

\section{Notes}

1. This research was supported by the Office of Naval Research, Group Psychology Branch.

2. Now at Purdue University. 